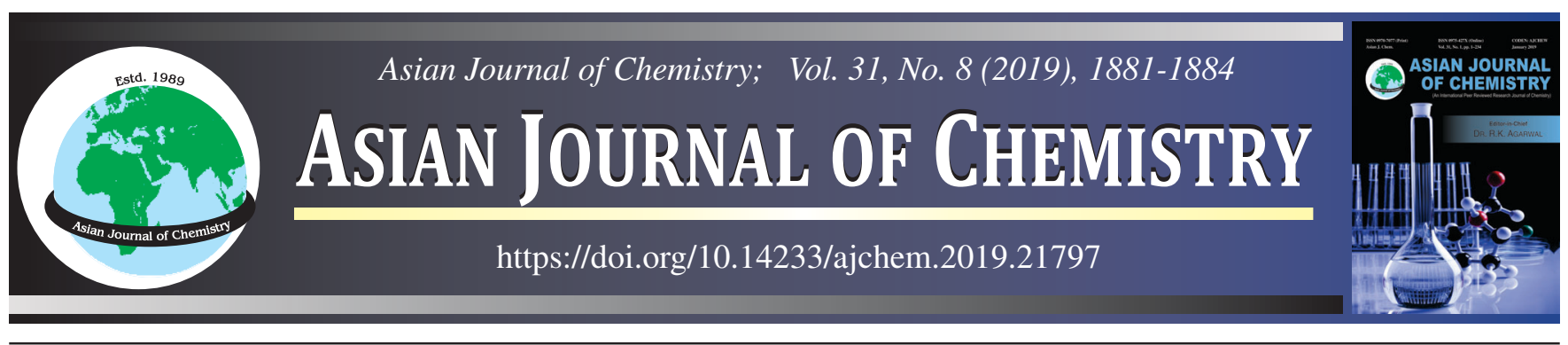

\title{
Green Synthesis of Silver Nanoparticles by Beta vulgaris \\ (Chard) Extract: Characterization and Antibacterial Activity
}

\author{
Rahma Hashim Abdullah ${ }^{1}$, Iman Fadhil ${ }^{2}$ and Amjed MirZa Oda ${ }^{3, *, \bullet}$
}

${ }^{1}$ Department of Soil and Water, Agriculture College, Al-Kasim Green University, Al-Kasim, Iraq

${ }^{2}$ Biotechnologies College, Al-Kasim Green University, Al-Kasim, Iraq

${ }^{3}$ Department of Science, Basic Education College, University of Babylon, Babylon, Iraq

*Corresponding author: E-mail: almajid1981@yahoo.com

Received: 15 November 2018;

Accepted: 23 May 2019;

Published online: 28 June 2019;

AJC-19470

\begin{abstract}
Green synthesis route has been used for preparation of silver nanoparticles (AgNPs) by aqueous extract of chard plant (Beta vulgaris). The extract volume was studied as effected parameter in the synthesis of AgNPs and monitored by UV-visible spectrum according to the surface plasmon resonance band that centered at $417 \mathrm{~nm}$. The silver nanoparticles were characterized by FTIR, XRD and SEM. The FTIR anlysis showed the adsorption of biomolecules on the AgNPs surface acting as reducing and capping agent. The XRD results revealed the presence of cubic face silver metal without trace of another silver oxides, as an indication of stability against oxidation. Also XRD in combination with SEM analysis showed that AgNPs are in the nanometric scale with spherical identical shape, where the route was successful. The silver nanoparticles tested against Streptococcus pneumonia and Escherichia coli, where the inhibition zone was 28 and $33 \mathrm{~nm}$, respectively.
\end{abstract}

Keywords: Green synthesis, Silver nanoparticles, Beta vulgaris, Capping agent.

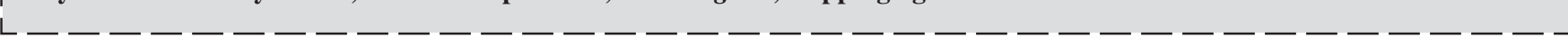

\section{INTRODUCTION}

Green synthesis of nanomaterials is very interesting method for preparing stable and multiuse nanomaterials in comparison to physical and chemicals techniques, where green synthesis depends on the action of biomolecules and work as reducing and capping agent without toxicity, eco-friendly and ease in manufacturing. In physical or chemical technique are cost in instrument or chemical agents and another limitation is low stability, contamination with residuals of agents and less compatibility in pharmaceutical and cosmetics industry [1-3]. Green synthesis serves as low cost techniques, rapid and one pot reaction, eco-friendly, environmentally safe, and easy to prepare stable nanomaterials, because all ingredients are biomolecules of structure or metabolites of plants as the active molecules that usually act to synthesize of nanometals by reduction [4,5].

Silver nanoparticles (AgNPs) have unique and interesting properties with high successive production, so AgNPs conquered a broad attention making them a good choice to be added in products that used by human, where AgNPs are relatively non- toxic, especially as drug or skin treatment [6]. Also AgNPs were took a large part in modern sciences for its properties like nanosize, distribution and morphology leads to variety in many applications such as catalysis, optics, electronics, magnetic and antibacterial activity [7-9]. The synthesis of nano silver particles nowadays are important field in nanotechnology researches as AgNPs are having individual inhibitory effect against many bacterial strains and microorganisms. This antibacterial activity of AgNPs gives enhancement to use in medicine to reduce infections in burn treatment [10].

Green synthesis using plant extracts such as citrus lemon [11], geranium leaves [12], curcumin [13], Camellia sinensis [14], Azhadirachta indica [15] have been successfully used to produce silver nanoparticles. The active components in extract are usually contain sugars, polyphenols, phenolic acids, terpenoids, alkaloids and proteins and these are representing reducing power which are responsible for the conversion of $\mathrm{Ag}^{+}$to $\mathrm{Ag}^{\circ}$. This synthesis route gives flexible control on the shape and size of nanoparticles. Thus in green synthesis, the role of extract is supplying of reduction power and as capping agent keeping

This is an open access journal, and articles are distributed under the terms of the Attribution 4.0 International (CC BY 4.0) License. This license lets others distribute, remix, tweak, and build upon your work, even commercially, as long as they credit the author for the original creation. You must give appropriate credit, provide a link to the license, and indicate if changes were made. 
size in narrow distribution and also stability of nanoparticles is relatively high $[12,15]$.

In this study, swiss chard (Beta vulgaris) was used for green synthesis of AgNPs. It is a biennial herb and leafy vegetable and its low cost and has a wide use in many dishes [16]. The leaves can be used in salads or cooked like spinach, and the stems are usually chopped and cooked like celery. The plant is more robust and easier to grow than spinach and celery. As reported the leaves have a concentrations of vitamins A, B and C, iron, calcium and phosphorus. Phytochemical analysis have showed the presence of fatty acids, glycolipids phospholipids, polysaccharides, folic acid, ascorbic acid, saponins, pectin, flavonoids, phenolic acids [17]. In this research, chard (beta vulgaris) leaves aqueous extract were used for synthesis of AgNPs to evaluate the reduction power of this extract as green route of AgNPs production. The effect of extract volume was studied and identified by UV-visible spectroscopy, FTIR, XRD, SEM and then the antibacterial activity action on Streptococcus pneumonia and Escherichia coli was studied.

\section{EXPERIMENTAL}

Preparation of plant extract: Chard (Beta vulgaris) had been collected from one of the grove of Al-Hilla city in Iraq, then it washed with water to remove dust and dirt and again washed with distilled water. To prepare extract, leaves were cut manually into small pieces, and then added $10 \mathrm{~g}$ of small plant pieces in a $100 \mathrm{~mL}$ of distilled water, and boiled on heater for $10 \mathrm{~min}$. Then the extract was filtered by filter paper to obtain a clear plant extract which was used for the preparation of silver nanoparticles.

Synthesis of AgNPs: To prepare AgNPs by plant extract, the specific volumes of plant extract was put in a $100 \mathrm{~mL}$ volumetric flasks, where 1,2 , and $4 \mathrm{~mL}$ of extract added to three flasks and made up the volume by adding aqueous solution of $0.001 \mathrm{M}$ of $\mathrm{AgNO}_{3}$. The mixtures were stirred and heated using thermal magnetic stirrer for $30 \mathrm{~min}$ at $70^{\circ} \mathrm{C}$. The colour of aqueous solution changed from colourless to brownish orange as an indication AgNPs were formed.

Characterization: The silver nanoparticles were characterized by several techniques to examine its properties and to ensure the green synthesis of nanomaterial of silver is produced. UV-VIS spectroscopy was used in the range 200-800 $\mathrm{nm}$ using quartz cuvettes and distilled water as blank. FTIR analysis were tested for AgNPs using $\mathrm{KBr}$ disk method in the range $4000-400 \mathrm{~cm}^{-1}$. Powder X-ray diffraction is tested for AgNPs by powder method, where AgNPs is decanted on glass slide several times to get thick film and tested in the range of $2 \theta 20$ $60^{\circ}$.

Bacterial strains and diagnosis: Two different clinical microbial isolates Gram positive and Gram negative Streptococcus pneumonia and Escherichia coli respectively were isolated from different clinical samples. During period from January to June, 2018 and identified by using conventional biochemical tests and Vitek 2 system (Biomeraux, France), and cultivated in pure culture at microbiological laboratory, College of Biotechnology, Al-Qasim Green University, Iraq.

Antimicrobial activity: Measuring of inhibition zone was done according to well diffusion method. To inoculate Mueller
Hinton agar plates evenly;abacterial suspension adjusted to $0.5 \mathrm{McFarland}$ standard $\left(1.5 \times 10^{8} \mathrm{CFU} / \mathrm{mL}\right)$ was used by sterile swab. Three wells were engraved on agar and then $100 \mu \mathrm{L}$ of AgNPs solution that prepared by adding 1,2 and $4 \mathrm{~mL}$ of extract. The plate was then incubated at $37^{\circ} \mathrm{C}$ for $18 \mathrm{~h}$ and in inverted position to look for a circular area of clearing around the wells. The diameter of the inhibition zone of the disc was measured to the nearest millimeter and The experiments were conducted in triplicates.

\section{RESULTS AND DISCUSSION}

The reduction of silver ions into silver nanoparticles can be visually examined after heating the aqueous solution of silver ions with Beta vulgaris extract. The primary solution is colourless and in the presence of active ingredient of extract, the colour changes into yellow-orange. This colour is belong to the surface plasmon-resonance (SPR) of AgNPs, which is intrinsic feature of AgNPs and can be detected by UV-visible spectra. Fig. 1 showed SPR peak centered around $417 \mathrm{~nm}$ and the same trend is observed at different volumes of extracts used. The silver nanoparticles are synthesized by the reduction of ions through the active biomolecules in plant extract, where these ingredients work as reducing agent. Also the peak at SPR is increased in intensity when plant extract concentration is increased, since reducing ability raised as the active ingredients are abundant in the high volumes of extract $[18,19]$.

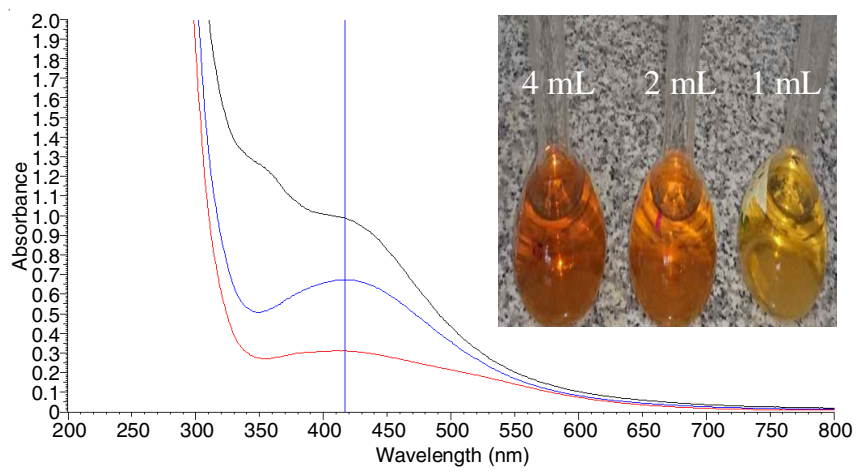

Fig. 1. UV-visible spectrum of AgNPs synthesized by beta vulgaris extract (1, 2 and $4 \mathrm{~mL})$

AgNPs were examined its nature by XRD spectrum to indicate the formation of one phase of silver. The XRD pattern of AgNPs that synthesized by plant extract is shown in Fig. 2, where the whole spectrum of $2 \theta$ values are ranging from $20^{\circ}$ to $80^{\circ}$. The main peaks are only at $2 \theta=38^{\circ}$ and $44^{\circ}$ and the rest are at noise level. These two peaks belong to FCC phase of silver according to XRD pattern that published by the Joint Committee on Powder Diffraction Standards (file no. 04-0783). As a comparison between XRD pattern and the standard of AgNPs is confirmed the formation of only silver phase. Also, a broad band centered at $2 \theta=20^{\circ}$ assigned to organic material of extract and this crystallization result from the adsorption of bioorganic ingredient of extract on the high surface area of AgNPs. As a conclusion, the extract efficiently convert ion to only AgNPs without oxide phases that mean the biomolecules in extract work as reducing agent and capping of AgNPs leads to more stability. According to the broadening of XRD peaks 


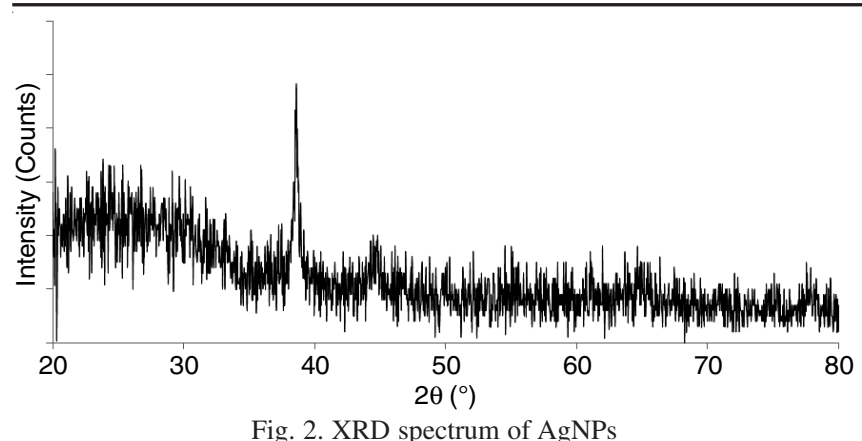

of AgNPs in the sample pattern indicated that AgNPs are in nanosizes and beneficial to estimate mean particles diameter through the line width of the maximum intensity reflection peak according to the Scherrer equation:

$$
\mathrm{D}=\frac{\lambda \mathrm{k}}{\beta \cos \theta}
$$

where $\mathrm{D}$ is the mean particle size, $\lambda$ is the wavelength of $\mathrm{X}$-ray used and $\theta$ is the Bragg angle, $\beta$ is the breadth of the pure diffraction profile in radians on $2 \theta$ scale and $\mathrm{k}$ is a constant approximately equals to unity and related both to the crystalline shape [20]. According to these calculations, the mean particle size was found equal to $25 \mathrm{~nm}$ and this result is an indication of successful synthesis of AgNPs by Beta vulgaris on the nanometric level.

SEM analysis: The morphology (Fig. 3) of AgNPs are very fine particles at nanometric scale with diameter between $30-50 \mathrm{~nm}$ with spherical shape and from SEM image it is observed that AgNPs are spherical, similar nanoparticle in all directions. This result is very interesting due to the extract power in addition of reduction, the ability to produce nanoparticles with limited range in size and identical in morphology.

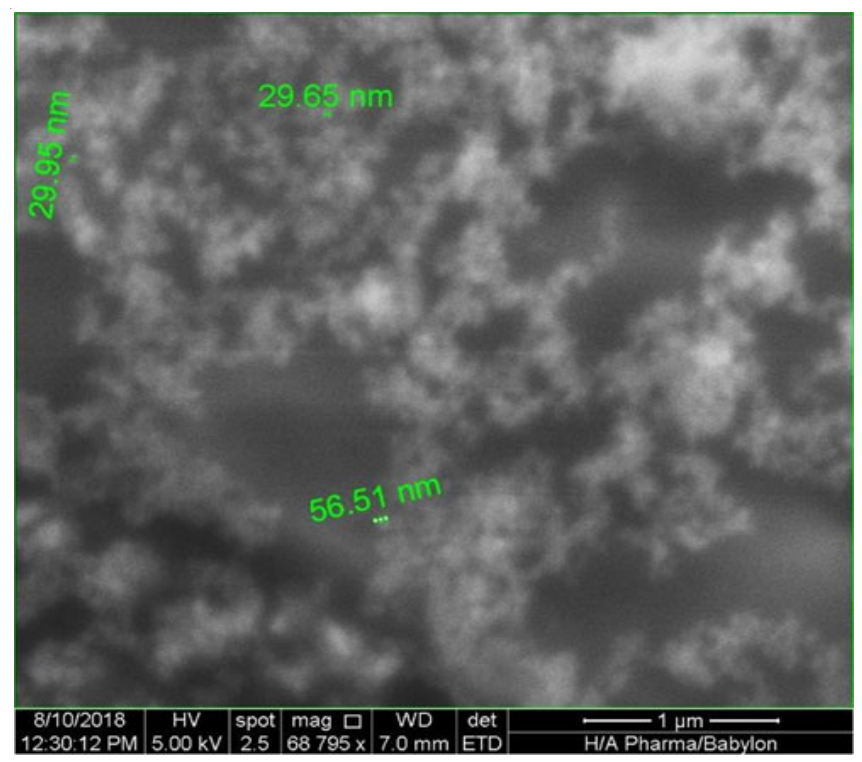

Fig. 3. SEM image of AgNPs

FT-IR analysis: FT-IR analysis (Fig. 4) demonstrate the functional group that responsible of $\mathrm{Ag}$ ion reduction, where the active ingredient of extracts are adsorbed on AgNPs that working as stabilizer in addition of involvement of synthesis.

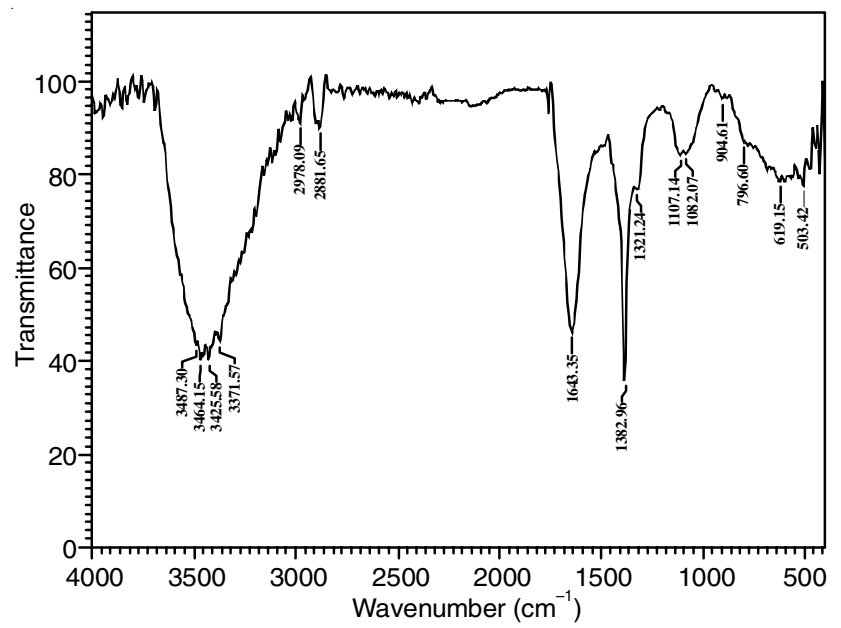

Fig. 4. FTIR analysis of AgNPs

The FT-IR spectrum (Fig. 4) of AgNPs showed several characteristic peaks; $\mathrm{O}-\mathrm{H}$ and $\mathrm{N}-\mathrm{H}$ appeared in the absorption band at 3487.3 and $3371.5 \mathrm{~cm}^{-1}, \mathrm{C}-\mathrm{H}$ band deformation at 2978 and $2881 \mathrm{~cm}^{-1}$, characteristic absorption band at about $1643 \mathrm{~cm}^{-1}$ for $-\mathrm{C}=\mathrm{O},-\mathrm{C}-\mathrm{N}$ asymmetric stretching at $1382.9 \mathrm{~cm}^{-1}$ or assigned to $\mathrm{NO}_{2}$ functional group and $\mathrm{C}-\mathrm{O}$ stretching at $1130 \mathrm{~cm}^{-1}$. A peak at $1384 \mathrm{~cm}^{-1}$ geminal methyl,1118 $\mathrm{cm}^{-1}$ (C-O-C), 717 $\mathrm{cm}^{-1}$ assigned to $\mathrm{C}-\mathrm{H}$ vibration; $1450 \mathrm{~cm}^{-1}$ assigned to $\mathrm{C}=\mathrm{C}$ stretching vibration of aromatic group and $599 \mathrm{~cm}^{-1}(\mathrm{C}=\mathrm{C})$ suggested the presence of flavanones or terpenoids which adsorbed on the surface of silver nanoparticles and finally band at $476 \mathrm{~cm}^{-1}$ due to deformation of silver nanoparticles [21].

Antibacterial activity: Antibacterial activity of AgNPs synthesized by Beta vulgaris extract was studied against Gram positive (S. pnemonae) and Gram negative (E. coli) bacteria. This study accomplished to prepare AgNPs by changing the volume of extract and fixed Ag ion concentration to describe how much AgNPs are affected by the volume of extract. The test of antibacterial took on account the variation of extract volumes, where each bacteria are affected by all volume ratio of extract. Extract volumes were used in the present experiments are 1,2 , and $4 \mathrm{~mL}$ added to $1 \mathrm{mM}$ of silver ions, where the total volumes was $100 \mathrm{~mL}$. All the petri dishes consisted the same volume of extract, where $100 \mu \mathrm{L}$ were added to wells in agar nutrient, and it was found that AgNPs prepared in different volumes of extract inhibited both bacteria in this study.

When the volume of extract was increased, the inhibition zone is more effective and increased in value. In this study the AgNPs has the high activity to kill bacteria according to toxicity of AgNPs which have affected on bioactivity of bacteria via DNA synthesis or membrane permeability. The second result is the volume of extract is limited parameter of AgNPs formation, where at high volume of extract the bioactivity is inhibited more and this is related to the abundance of AgNPs at high concentration than the AgNPs that prepared by addition of 1 or $2 \mathrm{~mL}$ of extract [22]. The AgNPs formation is increased when volume of extract is increased, where the amount of reduction is more as the active ingredients are much abundant in $4 \mathrm{~mL}$ than $1 \mathrm{~mL}$. The zone of inhibition of Streptococcus pneumonia and Escherichia coli was found to be 28 and 33 $\mathrm{mm}$, respectively. 


\section{Conclusion}

It is concluded that the extract of Beta vulgaris is convenient for the synthesis of AgNPs as green and eco-friendly material. The extract volume was effective parameter to synthesize AgNPs and high concentration of AgNPs was achieved at higher volumes. According to SEM and XRD analyses, the AgNPs were at a nanometric scale with spherical and identical shape. FTIR analysis revealed that the high surface area of AgNPs made adsorption surface of bioactive ingredients that belong to extract and acted as reducing and capping agent. The synthesized nanoparticles exhibited a high antibacterial activity against Streptococcus pnemonae and Escherichia coli.

\section{CONFLICT OF INTEREST}

The authors declare that there is no conflict of interests regarding the publication of this article.

\section{REFERENCES}

1. S.S. Shankar, A. Rai, A. Ahmad and M. Sastry, J. Colloid Interface Sci., 275, 496 (2004);

https://doi.org/10.1016/j.jcis.2004.03.003.

2. J.Y. Song and B.S. Kim, Bioprocess Biosyst. Eng., 32, 79 (2009); https://doi.org/10.1007/s00449-008-0224-6.

3. E.K. Elumalai, T.N.V.K.V. Prasad, V. Kambala, P.C. Nagajyothi and E. David, Arch. Appl. Sci. Res., 2, 76 (2010).

4. Z.A. Ali, S. Yahya, S.D. Sekaran and R. Puteh, Adv. Mater. Sci. Eng., 2016, 4102196 (2016);

https://doi.org/10.1155/2016/4102196.

5. R. Balagurunathan, M. Radhakrishnan, R. Babu Rajendran and D. Velmurugan, Indian J. Biochem. Biophys., 48, 331 (2011).

6. R. Bhattacharya and P. Mukherjee, Adv. Drug Deliv. Rev., 60, 1289 (2008); https://doi.org/10.1016/j.addr.2008.03.013.

7. A. Sivanesan, H.K. Ly, J. Kozuch, M. Sezer, U. Kuhlmann, A. Fischer and I.M. Weidinger, Chem. Commun., 47, 3553 (2011); https://doi.org/10.1039/c0cc05058j.

8. A.N. Shipway, E. Katz and I. Willner, Chemphyschem., 4, 18 (2000); https://doi.org/10.1002/1439-7641(20000804)1:1<18::AIDCPHC18>3.0.CO;2-L.
9. W.A. Ismail, Z.A. Ali and R. Puteh, J. Nanomater, 2013, 901452 (2013); https://doi.org/10.1155/2013/901452.

10. D.V. Parikh, T. Fink, K. Rajasekharan, N.D. Sachinvala, A.P.S. Sawhney, T.A. Calamari and A.D. Parikh, Text. Res. J., 75, 134 (2005); https://doi.org/10.1177/004051750507500208.

11. T.C. Prathna, N. Chandrasekaran, A.M. Raichur and A. Mukherjee, Colloids Surf. B Biointerfaces, 82, 152 (2011); https://doi.org/10.1016/j.colsurfb.2010.08.036.

12. S.S. Shankar, A. Ahmad and M. Sastry, Biotechnol. Prog., 19, 1627 (2003); https://doi.org/10.1021/bp034070w.

13. K. Varaprasad, Y.M. Mohan, K. Vimala and K.M. Raju, J. Appl. Polym. Sci., 121, 784 (2011); https://doi.org/10.1002/app.33508.

14. A.R. Vilchis-Nestor, V. Sánchez-Mendieta, M.A. Camacho-López, R.M. Gómez-Espinosa, M.A. Camacho-López and J.A. Arenas-Alatorre, Mater. Lett., 62, 3103 (2008);

https://doi.org/10.1016/j.matlet.2008.01.138.

15. A. Lalitha, R. Subbaiya and P. Ponmurugan, Int. J. Curr. Microbiol. Appl. Sci., 2, 228 (2013).

16. S. Bolkent, R. Yanardag, A. Tabakoglu-Oguz and Ö. Özsoy-Saçan, $J$. Ethnopharmacol., 73, 251 (2000); https://doi.org/10.1016/S0378-8741(00)00328-7.

17. Z.-J. Gao, X.-H. Han and X.-G. Xiao, Food Chem., 117, 342 (2009); https://doi.org/10.1016/j.foodchem.2009.04.013.

18. H. Kolya, P. Maiti, A. Pandey and T. Tripathy, J. Anal. Sci. Technol., 6, 33 (2015); https://doi.org/10.1186/s40543-015-0074-1.

19. S.P. Dubey, M. Lahtinen, H. Särkkä and M. Sillanpää, Colloids Surf. B Biointerfaces, 80, 26 (2010); https://doi.org/10.1016/j.colsurfb.2010.05.024.

20. M. Yildiztekin, S. Nadeem, F. Yildiztekin, O. Varol, M.A. Ozler and A.L. Tuna, Indian J. Pharm. Sci., 79, 536 (2017); https://doi.org/10.4172/pharmaceutical-sciences.1000260.

21. K. Venugopal, H. Ahmad, E. Manikandan, K.T. Arul, K. Kavitha, M.K. Moodley, K. Rajagopal, R. Balabhaskar and M. Bhaskar, J. Photochem. Photobiol. B, 173, 99 (2017); https://doi.org/10.1016/j.jphotobiol.2017.05.031.

22. F. Mirzajani, A. Ghassempour, A. Aliahmadi and M.A. Esmaeili, Res. Inmicrobiol., 162, 542 (2011); https://doi.org/10.1016/j.resmic.2011.04.009. 